\title{
Land value is a progressive and efficient property tax base: Evidence from Victoria
}

\author{
Cameron K. Murray*, Jesse Hermans ${ }^{\dagger}$ \\ January 19, 2021
}

\begin{abstract}
Property taxes are a common revenue source for city governments. There are two property tax bases available - land value (site value, SV), or total property value (capital improved value, CIV). The choice of property tax base has implications for both the distribution and efficiency of the tax. We provide new evidence in favour of SV being both the more progressive and efficient property tax base. First, we use three Victorian datasets at different levels of geographic aggregation to model the $\mathrm{SV} / \mathrm{CIV}$ ratio as a function of various household income measures. At all three levels, a higher SV/CIV ratio occurs in areas with higher incomes, implying that SV is the more progressive property tax base. Our range of results suggests that a one percent increase in the income of an area is associated with a 0.10 to 0.57 percentage point increase in the SV/CIV ratio. Second, we use historical council data to conduct a difference-in-difference analysis to compare the effect of switching from a CIV to SV tax base on the number of building approvals and value of construction investment. We find that switching from CIV to SV as a property tax base is associated with a $20 \%$ increase in the value of new residential construction. This is consistent with the view that changes to land value tax rates are non-neutral with respect to the timing of capital investment on vacant and under-utilised land. We also demonstrate theoretically this incentive to bring forward investment.
\end{abstract}

Keywords and phrases: Property tax, land value, capital improved value, progressivity, efficiency.

\footnotetext{
${ }^{*}$ Corresponding Author. Henry Halloran Trust, The University of Sydney, Camperdown, NSW 2006 Australia. Email: c.murray@sydney.edu.au.

${ }^{\dagger}$ Prosper Australia, North Melbourne, VIC 3051 Australia. Email: jesse.hermans@prosper.org.au.
} 


\section{Introduction}

Despite centuries of taxation applied to land values (site values, SV) or total property value including capital improvements (capital improved value, CIV), there remains no consensus amongst economists about which tax base is superior in terms of equity and efficiency (Drew \& Dollery 2015; Duke \& Gao 2018; Oates \& Fischel 2016; Plummer 2010). Resolving this debate is important in light of numerous historical and proposed council taxation changes in Australia and elsewhere (Freebairn 2020). In New Zealand, for example, $63 \%$ of councils now use a CIV property tax base, up from $14 \%$ in 1985 (IPART 2016, p.184). In Victoria, Australia, all 79 councils now use CIV as the base for their own taxation, raising $\$ 5.4$ billion from this property tax base in 2018-19 (ABS 2020). ${ }^{1}$ However, prior to Victorian council amalgamations that took place in the mid-1990s, 55 our of 210 councils used SV for their property tax base (Anderson 1996). Alongside council taxes, state land taxes are applied using a rising-block schedule of tax rates to the SV property tax base across Australia, typically with exemptions for owner-occupied residences and agricultural properties (SRO 2021).

There are two competing positions on property tax progressivity, which we define here as being a higher tax incidence on those with a higher ability-to-pay. The first position has come to dominate public debates, and that is that "land values are correlated only weakly with income or with ability to pay" and therefore "[p]roperty values or income are better indicators of ability to pay than are land values" (Abelson 2006, p.5). This position has been taken by numerous public agencies and think-tanks in Australia and New Zealand (Abelson 2006; DEWLP 2019b; IPART 2016; Shand et al. 2007). The other position, which we provide evidence for in this paper, is that land values are the more progressive tax base as the ratio of SV to CIV is positively related to income, meaning that property owned by wealthier people tends to be more land-intensive and therefore a tax on SV will have a higher incidence on those with a higher ability to pay.

To determine which property tax base is more progressive, we analyse the relationship between the SV/CIV ratio and household incomes in Victoria, Australia, at three levels of geographic aggregation; the local government area (LGA, or council), statistical area 2 (SA2), and statistical area 1 (SA1). ${ }^{2}$ Each level of aggregation has particular data advantages that allow for the robustness of any relationship to be tested. For example, the LGA level data is the most geographically aggregated (79 areas in Victoria) but has separate residential SV and CIV values, which allows different property types to be tested

\footnotetext{
${ }^{1}$ Five councils use the Net Annual Value (NAV) approach to property value base for tax purposes. NAV is defined as $5 \%$ of the CIV for residential and rural properties, thereby making it equivalent to CIV for these property types. However for industrial and commercial properties, the NAV is an estimate of the gross rental value of the property. The five councils using NAV valuation are Glen Eira City Council, Melbourne City Council, Port Phillip City Council, Whittlesea City Council and Yarra City Council.

${ }^{2}$ There are four SA levels in the Australian Statistical Geography Standard (ASGS), which is the main geographical subdivision method used by the Australian Bureau of Statistics (ABS). SA1 is the smallest level, with each SA1 area having a population of 427 on average in Victoria.
} 
independently. SA2 data is more disaggregated (396 areas in Victoria), with five SA2 areas per LGA, but includes only SV and CIV for all property types combined. SA1 is the most disaggregated geographic level (12,899 areas in Victoria). It also includes only SV and CIV for all property types combined and instead of direct household income measurements contains socio-economic status indexes which capture the ability to pay element of interest. As our data becomes more geographically disaggregated, and hence relevant to the question of the distribution of taxes within LGAs, it also becomes less representative of the income and tax base relationship due to differing homeownership rates and proportions of nonresidential property. Conducting the analysis at all levels demonstrates the robustness of the relationship.

We show that the relationship between the SV/CIV ratio and income is positive and significant at all levels of geographic aggregation, indicating that SV is a more progressive property tax base. Because of this, it is likely that if councils raised the same revenue from SV rather than CIV it would reduce the property taxes paid by the majority of property owners, increasing the value of their properties (Brueckner 1986; Yang 2018).

We further argue that there are efficiency grounds for favouring a transition from a CIV to SV tax base for council rates. For our purposes, efficiency is defined as productive concept, not an allocative one, and is observed by the utilisation of fixed land inputs for higher value uses via capital investment. Land value taxes create incentives to accelerate investment in capital improvements on land, increasing productive capacity. Earlier work has demonstrated the dynamic incentive effect of land value taxes (which are otherwise nondistortionary in static terms) and we expand on this to show how this transition increases the rate of tax on vacant and under-utilised properties and makes delaying investment on these properties more costly (Bentick 1979; Mills 1981; Pollock \& Shoup 1977). Since it is these properties that have the scope to respond to incentives to bring forward investment, the effect on increasing capital investment in housing, commercial, and industrial buildings could be substantial. Recent policy debates on property tax efficiency, however, have been less concerned with reducing dynamic tax distortions and more focussed on reflecting a market price for council-provided services, which conflicts with the typical economic logic of tax efficiency (IPART 2016).

To demonstrate the potential scale of the investment effect from changing the property tax base from CIV to SV we use data from 26 Victorian local councils, who changed their tax base from CIV to SV at different times during the 1952 to 1984 period, showing that taxing SV rather than CIV is related to a $20 \%$ increase in the value of new dwelling construction. This evidence, together with the evidence of the progressivity of SV as a property tax, suggests there are significant economic gains from using SV as the property tax base instead of CIV. 


\section{Background}

The debate about the progressivity and efficiency of property taxation has a long history, often driven by the financial interests of property owners who argued that it was regressive compared to alternatives like sales and payroll taxes (Gaffney 1971). While the evidence seems clear that taxation of either a CIV or SV base is progressive, the relativeness of each is still debated in the literature and could be dependent on the patterns of existing development, the nature of exemptions, and the distribution of homeownership (Barbosa \& Skipka 2019; Bowman \& Bell 2008; Drew \& Dollery 2015; England \& Zhao 2005; Oates \& Fischel 2016; Plummer 2010).

In policy debates, the issue of progressivity is often overlooked or misinterpreted as the strength of a linear relationship between the tax base value and household income. For example, in a review of New South Wales property taxation, IPART (2016) relied on analysis in Shand et al. (2007) and comments by Abelson (2006) to note that "CIV is more highly correlated with annual household income than SV" and conclude that "property values or income are both better indicators of ability to pay than are land values." But this conclusion does not follow. Shand et al. (2007) compared the estimated slopes of two linear models; one relating CIV to income and one relating SV to income. This does not demonstrate which is the more progressive tax base, or which better reflects a household's ability to pay. If both bases are positively and linearly related to income, and the intercept is near zero (as is usually the case), then both tax bases are equally progressive. A tax on land value at the ratio of the slopes times the tax rate on CIV will raise an equal amount of money and be equally distributed across income levels. In this case, the slope was 4.3 for CIV and 1.8 for $\mathrm{SV}$, so a tax on $\mathrm{SV}$ at $\frac{4.3}{1.8}=2.4$ times the tax rate on CIV will raise an equal amount of money in an equally progressive manner. There is no implication about a distributional effect because the comparison of two linear models embeds an assumption of an equal SV/CIV ratio at all income levels. Assessing the distributional effect from a shift between the CIV and SV tax base requires applying a non-linear model, a non-linear transformation of the data, or a direct analysis of the SV/CIV ratio, which is the approach taken here.

One established distributional effect is that shifting the property tax base from CIV to SV reduces taxes and therefore increases prices for the majority of properties (Brueckner 1986; Yang 2018). This happens because the distribution of the SV/CIV ratio is typically not symmetrical - the tax increase on the minority of properties with few, or no, capital improvements offsets a tax decrease on the majority of properties. Indeed, the fact that switching to a CIV base increases taxes on the majority of properties has attracted councils to this tax base as they see it as a more sustainable source of revenue and potentially less volatile due to land market cycles (DEWLP 2019b).

Revenue volatility is not usually a concern for councils in Australia. Council revenues are set based on budget targets, then the tax rate is set in order to get this revenue by dividing the revenue target by the total property tax base value. Even if the value of the tax base 
varies, the tax rate applied to it will automatically vary to stabilise revenues. Notably, since 2016 the Victorian government has limited the ability of councils to increase rates by adopting a cap on the increase in total rates revenue, which is currently $2 \%$ (ESC 2021). This has the effect of lowering the rate per dollar of tax on the council's CIV base. Councils can exceed the cap to fund spending if approved by the Essential Services Commission (ESC) (ESC 2020). This approach is different to the State government's use of their SV property tax base for land tax purposes, where it applies a rising-block schedule of rates to taxable land holdings of individuals or companies, with rates on the dollar fixed since 2009 (SRO 2021). In terms of the valuation approach used, both SV and CIV are assessed based on highest and best use.

In terms of the relative efficiency of each tax base, there are two competing underlying principles. The first is the common economic principle of surplus maximisation by minimising distortions. The competing efficiency principle is the beneficiary principle, which assumes that efficiency is maximised when recipients of local government services pay in proportion to the value of services they receive. The beneficiary principle is argued to justify CIV as a property tax base because CIV reflects the intensity of the use of local services, with occupants of developed property using more local services than a vacant property. Yet the value of local services and amenity are reflected in SV, not CIV. The difference between SV and CIV is the capital value of improvements, which is unaffected by changes in the provision of local services (Comrie 2013). Taxing these improvements simply adds friction to investment decisions. Additionally, vacant and under-developed property is inefficient in terms of the agglomeration effects from the co-location of land uses. Taxing vacant property at a higher rate (which happens automatically when shifting from a CIV to SV base) encourages more efficient land use and raises the funds for services for future occupants before they are needed. Without resolving this debate, we merely concentrate our analysis on the first efficiency principle, as we see it as the more relevant principle for government revenue-raising at all levels.

We expect taxation of SV to be superior to CIV based on the first efficiency principle of surplus maximisation because of dynamic incentive effects. As Bentick (1979) and Mills (1981) have noted, when there is a choice between investing in improvements on vacant (or under-utilised) property now or later, a tax on land value "favors the project with the early- payoff income stream' '(Mills 1981, p.127). Since a tax on land value is, in effect, an increase in the cost of delay, it reduces the distortions that arise from the option to delay development. Because a tax on SV will be levied at a higher rate per dollar of value, and properties with the most scope for development will have the highest SV/CIV ratios (with $\mathrm{SV}$ equal to CIV for vacant land), a switch to an SV base targets this incentive on those properties that have the highest scope for additional capital investment.

To demonstrate this effect theoretically, we show how a tax on SV and CIV changes the condition for choosing an investment project that is delayed over an immediate project. Assume that Project $A$, which is the immediate project choice, earns rent $_{A}$ and has a construction cost $c_{A}$, Project $B$, is the delayed project choice, constructed later at time 
$T$ and earning total rent $_{B}$ with a construction cost $c_{B}$. Compared to no tax on property, implementing a property tax, $b$, usually makes the choice to delay a more difficult one. How much the property tax affects the choice to delay depends on the choice of base. The conditions in which delaying and choosing Project B are favourable for three scenarios - no tax, tax on SV, and tax on CIV - are in Equation 1, which uses as discount rate $r$ (these are derived in the Appendix).

$$
\begin{aligned}
& \text { No tax: }\left(\text { rent }_{A}-c_{A} r\right)<e^{-r T}\left(\text { rent }_{B}-c_{B} r\right) \\
& \text { SV tax: }\left(\text { rent }_{A}-c_{A} r\right)<e^{-(r+b) T}\left(\text { rent }_{B}-c_{B} r\right) \\
& \text { CIV tax: }\left(\text { rent }_{A}-c_{A} r\right)<e^{-(r+b) T}\left(\text { rent }_{B}-c_{B} r\right)+b\left(c_{A}-e^{-(r+b) T} c_{B}\right)
\end{aligned}
$$

Notice that without a tax the net return of Project B (i.e. $\left(\right.$ rent $\left._{B}-c_{B} r\right)$ ) needs only be discounted by the rate $r$ to be a favourable choice. In terms of growth rates, this means that delay is preferred if the growth rate of net revenue from delaying exceeds $r$. But when a tax on SV is introduced, the existence of the periodic tax payment prior to time $T$ increases the cost of delay and now the net return of Project B must exceed Project A when discounted at the higher rate of $(r+b)$. This is a more challenging economic hurdle for the choice to delay, and in growth rate terms means that net revenue growth from delaying must now exceed $r+b$.

Finally, a tax on CIV comprises the effect of the tax on the SV component of CIV (in the first term on the right hand side of the equation) and the effect of the tax on construction (in the second term). If the discounted construction cost of Project B at the higher $(r+b)$ rate is more than the construction cost of Project $\mathrm{A}$, then the same rate property tax per dollar of base value, $b$ has a diminished dynamic incentive effect when applied to CIV rather than SV. CIV will have a higher incentive effect if future costs for Project B grow at less than the rate $(r+b)$. Since higher value projects are more dense, requiring higher construction costs to account fo the larger floor area needed to capture the higher rents, the construction tax effect term may occasionally be positive rather than negative.

To demonstrate this effect we solve for the optimal time delay with a simple numerical example $^{3}$, showing that without tax the optimal delay is 7.1 years, with a $2 \%$ tax on SV the optimal delay is 4.8 years, and with a $2 \%$ tax on CIV the optimal delay is 7.7 years. However, this does not demonstrate the relative efficiency of a tax on SV compared to $\mathrm{CIV}$, since the tax rate per dollar on $\mathrm{SV}$ is going to be much higher to collect the same total revenue; around $70 \%$ higher according to our Victorian data where the mean SV/CIV ratio of 0.59 in 2016. Using this example, we then increase the tax rate per dollar of SV from $2 \%$ to $3.4 \%$, and find that the optimal time delay is 3.9 years, which we can directly compare with the delay of 7.7 years from a $2 \%$ tax rate on CIV. Thus we expect that the combination of the incentive effect of switching to an SV base, plus the effect of increasing the rate, will have substantial effects on the rate of new construction. Switching from

\footnotetext{
${ }^{3} r=0.04, b=0.02, c_{A}=100, c_{B}=107$, rent $_{A}=8$, rent $_{B}=9.6$
} 
a CIV to SV base only increases the total tax paid on the minority of properties that are vacant and under-utilised land (with above average SV/CIV ratio). This means that the incentive effect of SV is highly targeted to properties that have scope for additional construction investment.

The empirical literature on these efficiency effects is small, but the effects themselves seem large. Oates \& Schwab (1997), for example, found a $47 \%$ increase in building permits following the 1979 increase of tax rate on land value in Pittsburgh, Pennsylvania. Cho et al. (2011) found that an increase in the SV tax rate increased density and the likelihood of development in Nashville-Davidson County, Tennessee. More recently, modest density effects from increasing the CIV tax rate were found by England et al. (2013), who note that "ten percent tax hike would increase the floor-area ratio of the average new home by about 2.2 percent".

We note that these efficiency effects are likely to be present in state land tax systems that apply to SV in Victoria and elsewhere, which can result in significant increases in land taxes on undeveloped land when prices are rising, changing development incentives. However, owner-occupier and primary-production exemptions mean that this effect is smaller than it would otherwise be.

\section{Data and methods}

\subsection{Data}

We use total unimproved site value (SV) and capital improved value (CIV) for Victoria, Australia, at three levels of aggregation; the local government area (LGA, or council), Statistical Area 2 (SA2), and Statistical Area 1 (SA1). While a shift from a CIV to SV tax base for councils will have only within-LGA distributional effects, making the smallest SA1 data most relevant, we also conduct our analysis at more aggregated geographic levels for two reasons. First because state governments also levy taxes on property (presently on SV) and the consequences of potentially changing their tax base to CIV are of interest. And second, because each set of data has specific characteristics that can provide additional insight.

At all levels, the SV and CIV data for all land uses types combined comes from valuations estimated by the State Valuer General, which means they perfectly match the base upon which taxes would be levied. However, only at the LGA-level is data available by property type, allowing us to separate out the progressivity in terms of residential property values from non-residential properties, where ownership is concentrated at the top end of the income distribution. At the LGA level we are able to use more recent 2016 valuations data and match it to both median household incomes and equivalised disposable incomes ${ }^{4}$

\footnotetext{
${ }^{4}$ Equivalised disposable household income nets out taxes from gross incomes and adjusts for household size to provide a standardised metric of a household's economic well-being.
} 
sourced from the census of the same year, providing 79 LGA-level data points (ABS 2018, 2019a; DEWLP 2019a).

There are five SA2 areas per LGA on average across Victoria. This level of data gets closer to answering the within-LGA distribution question, but data on SV and CIV by property type are not available. The data comes from a 2011 experimental land account released at the SA1 level and is aggregated to the SA2 level to match the multiple household income metrics available at the SA2 level (ABS 2012). Data on the renter share in each SA2 allows us to add relevant controls. However, with so few areas per LGA this level of aggregation is still too high to cleanly answer our main question.
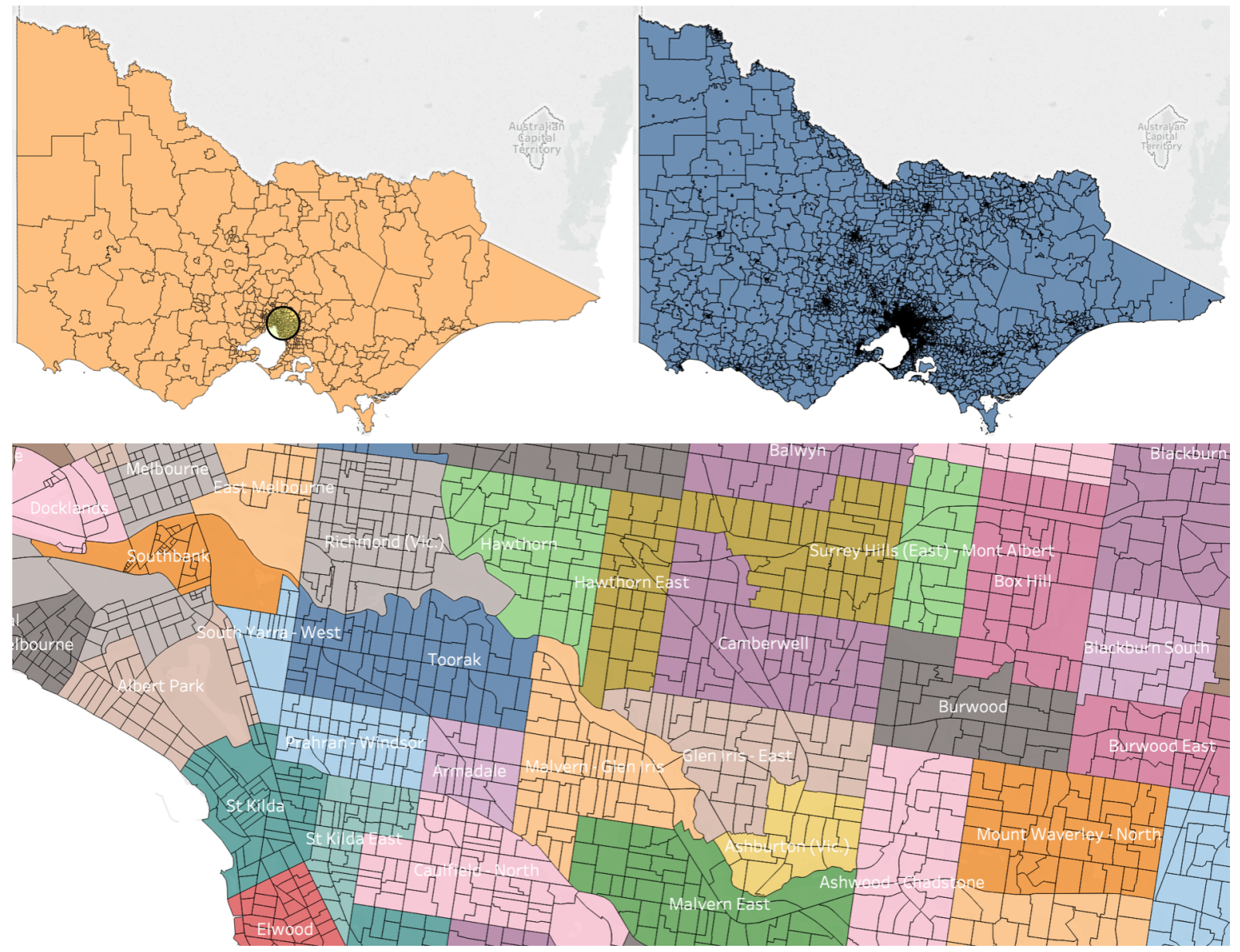

Figure 1: SA2 (left) \& SA1 (right) areas. SA1 shaded by SA2 at marked location (bottom)

SA1 levels are much smaller, as can be seen in Figure 1, with 163 SA1 areas per LGA on average. This level of aggregation is most appropriate for assessing the within-LGA distribution of taxing an SV or CIV base. However, rather than direct income measurements to represent a household's ability to pay, four indexes of socio-economic status that account 
for income and wealth in their composition are available at this level (ABS 2011). ${ }^{5}$ Though these are not direct income measures, by incorporating wealth, family size, and education into their composition, they could be argued to better represent a household's ability to pay property taxes than simple income metrics. Table 1 shows the key data features at each level of geographic aggregation, while Table A.1 in the Appendix provides a summary of the variables in each dataset. Notice that residential properties dominate as a share of total property values in each council and that $7 \%$ of residential lots were vacant in the typical Victorian council. The mean SV/CIV ratio is 0.59 , which means that the tax rate per dollar on the smaller SV base would need to be $70 \%$ higher to generate the same total revenue on average if all councils in Victoria shifted to an SV base.

Table 1: Data features at each geographic level

\begin{tabular}{lcccc}
\hline \hline & $\begin{array}{c}\text { SV \& CIV } \\
\text { by property } \\
\text { type }\end{array}$ & Renter share & $\begin{array}{c}\text { Household } \\
\text { income }\end{array}$ & $\begin{array}{c}\text { Socio- } \\
\text { economic } \\
\text { status }\end{array}$ \\
\hline LGA & Yes & Yes & Yes & No \\
SA2 & No & Yes & Yes & No \\
SA1 & No & No & No & Yes \\
\hline \hline
\end{tabular}

A limitation of the data is that the incomes of renting households and owners in each area are pooled in the income data, yet renters will not pay property tax. Additionally, at the SA2 and SA1 levels, SV and CIV data include all property types, with around 40\% being non-residential property. The owners of rental and non-residential properties will be pooled in the area they live, rather than where the properties they own are located. This will likely mean that the analysis underestimates the progressiveness of a tax on either an SV and CIV base, as household income and the ownership of non-owner-occupied property is closely related. The top equivalised income quintile has 5.1 times the income of the bottom quintile and owns 5.5 times as much property wealth (excluding owner-occupied housing) (ABS 2019b). Any results about progressiveness with respect to income are likely to be amplified because the wealthiest and highest-income households will also pay taxes on their investment property. We cannot claim this has no bearing on the relative progressiveness of each base. However, for this to undermine the general patterns we find, the relationship between the SV/CIV ratio and income for non-owner occupied property

\footnotetext{
${ }^{5}$ The four indexes are Index of Relative Socio-economic Advantage and Disadvantage (IRAD), the Index of Relative Socio-economic Disadvantage (IRD), the Index of Economic Resources (IER), and the Index of Education and Occupation (IEO). These are described in ABS (2011). These indexes are compiled from numerous income, wealth, housing, education, occupation, and family characteristics. IRD differs from IRAD in that it summarises characteristics of relative socio-economic disadvantage only. IER mainly summarises the economic resources of households based on income and wealth indicators. IEO summarises the level of formal education and occupation types to provide an index of socio-economic advantage related to skills and jobs.
} 
owned outside the owner's geographic area must be the opposite of the overall relationship, which is we believe is unlikely.

To study the efficiency of a transition between a CIV and SV tax base we use historical data compiled by the Melbourne Metropolitan Board of Works (MMBW) for 26 predominantly rural Victorian local councils between 1952 and 1984. We track the number and construction value of dwellings built each year for at least two years prior, and three years following, a change in their tax base from CIV to SV (7.5 years of data on average for each council, with 2.7 years pre-, and 4.7 years post-change) (Kavanagh 1975, 1985). ${ }^{6}$ This provides us a panel of 190 data points that we use to tease out any efficiency effect of switching from a CIV to SV tax base in terms of additional housing construction. The fact that councils made the tax changes independently at different times between 1955 and 1982 gives us confidence the interpretation of this analysis as the data has features of a natural experimental condition. ${ }^{7}$ Each council tax change was the result of independent local council referendums that occurred in different years.

\subsection{Methods}

To compare the relative progressivity of CIV and SV in terms of our household income metrics we model the SV/CIV ratio in each area as a function of household income metrics in the form

$$
V_{i}=\alpha+\beta \ln \left(\operatorname{Inc}_{i}\right)+\gamma C_{i}+\epsilon
$$

where $V_{i}$ is the SV/CIV ratio for each $i$ area, $I n c_{i}$ is a household income metric for that area, and $C_{i}$ are controls where applied, such as rental share of households (for LGA and SA2 levels), and $\alpha$ is a constant. We conduct numerous model variations, for example by using only residential property or all property types at the LGA level, allowing us to assess the robustness of the relationship with each income and wealth metric. $\beta$ can be interpreted as the percentage point change in the SV/CIV ratio associated with a percent increase in incomes. Therefore a positive $\beta$ indicates that SV is a more progressive tax base as higher-income households will pay a higher share of property tax revenue under SV.

We complement this approach by directly calculating a measure of the change in the progressivity of the property tax, in this case, the Kakwani index. This index is the difference between the Gini coefficient of tax liability under each property tax base, or

\footnotetext{
${ }^{6}$ The original choice of rural council data was because of the large variation in metropolitan councils with rapid housing projects commencing in different suburbs over the study period. Kavanagh (1975) notes, however, that for metropolitan councils "even more impressive figures could be shown for most of the suburban cities and shires which have un-taxed buildings." We have also included South Melbourne council in this data from Kavanagh (1972).

${ }^{7}$ Years with one council making the tax base transition: 1965, 1970, 1971, 1972, 1982. Years with two councils: 1957, 1960, 1962, 1964. With three councils: 1955. With four councils: 1958, 1959.
} 
$G_{S V}-G_{C I V}$, where $G=\frac{2}{n} \sum_{k=1}^{n}\left(\sum_{i=1}^{k} \omega_{i}-\lambda_{i}\right)$, with $n$ being the population of areas in the analysis, $k$ being the index of individual areas ordered by income share, $\omega_{i}$ being the income share of area $i$, and $\lambda_{i}$ being the area's share of taxes paid (either SV or CIV). A positive result for this calculation indicates greater progressivity from an SV property tax base. We also plot Lorenz curves for both property tax bases to demonstrate this effect visually.

To achieve our secondary task of examining the economic efficiency of each tax base, we estimate the relationship between our investment variables in the following form

$$
\ln \left(D_{i, t}\right)=\alpha+\beta S V_{i, t}+\gamma C_{i, t}+\epsilon
$$

where $D_{i}$ is the number of dwellings permitted in council $i$ in year $t$ (or the value of residential construction in that year), $S V_{i, t}$ is a dummy variable for using $\mathrm{SV}$ as the tax base rather than CIV, $C_{i, t}$ are year and council controls, and $\alpha$ is a constant. A positive $\beta$ indicates that an SV tax base is associated with more dwelling investment.

\section{Results}

\subsection{Progressivity}

Table 2 summarises the main regression results (Equation 2 and its variations) at the LGA level and the progressivity change, with Models 1 and 2 using the SV/CIV ratio for all land use types as the independent variable, and Models 3 and 4 using the SV/CIV ratio for residential land only. For all models, the two income variables are positively correlated with the SV/CIV ratio, indicating that higher income areas have a larger share of property wealth in land rather than buildings. Because of the log transformation of the independent variable we can interpret the results to mean that a $1 \%$ increase in the median gross household income in an LGA is associated with a 0.11 to 0.21 percentage point increase in the SV/CIV ratio, confirming our expectation that a property tax on the SV base is more progressive.

For the index of progressivity change from the tax switch we can see that an increase of about $2.6 \%$ in the Gini index from the switch, indicating an increase in progressivity. Because the CIV property tax is not especially progressive in terms of gross household incomes, in relative terms this increase is quite large, between $7 \%$ and $53 \%$ depending on the which property types and incomes are used in the analysis. Figure A.2 of the Appendix shows this effect visually.

Figure A.1 of the Appendix plots the SV/CIV data for all property types (top row) and residential property only (bottom row), visually showing a key result, which is the stronger relationship between income and the SV/CIV ratio for residential property. ${ }^{8}$ This result

\footnotetext{
${ }^{8}$ The best fit lines come from the model without renter share controls and are hence not the slope
} 
Table 2: SV/CIV ratio analysis and progressivity index (LGA level)

\begin{tabular}{lllll}
\hline \hline & \multicolumn{2}{l}{ All property types } & \multicolumn{2}{l}{ Residential only } \\
& 1 & 2 & 3 & 4 \\
\hline Median gross inc. & $0.11^{* *}$ & & $0.21^{* * *}$ & \\
Mean eq.disp.inc. & \multicolumn{4}{l}{$0.30^{* * *}$} \\
Renter share & -0.00 & $-0.004^{* * *}$ & $0.003^{*}$ & $-0.003^{* * *}$ \\
\hline $\mathrm{R}^{2}$ & 0.07 & 0.30 & 0.15 & 0.52 \\
\hline Kakwani index & 0.026 & 0.027 & 0.025 & 0.026 \\
Relative Gini increase & 0.53 & 0.09 & 0.32 & 0.07 \\
\hline \hline & ${ }^{*} p<0.1,{ }^{* *} p<0.05,{ }^{* * *}$ & $p<0.01$. & $N=79$. Dependent variable is $\mathrm{SV} / \mathrm{CIV}$ \\
ratio at LGA level. Income variables are the log of weekly income.
\end{tabular}

may be because the owners of residential property at the LGA level are more likely to live in the area (with $75 \%$ of household being owner-occupiers) than owners of non-residential property. This does not indicate that a property tax applied to an SV base for all property types is less progressive, as the ownership of non-residential property is skewed towards the top of the income distribution (ABS 2019b).

At the SA2 level we replicate this modelling exercise and present the results in Table 3. Here we have three income metrics available, with each showing a clear positive relationship with the SV/CIV ratio. Including the renter share variable is important, as there are a number of SA2 areas that have high incomes and low SV/CIV ratios, but are also very high rental rates. For example, Docklands, an inner-city area of Melbourne comprising mostly newly-built apartments, has high-income households but the lowest SV/CIV ratio of 0.13. It also has a renter share of $62 \%$. The plots of the data in Figure A.3 of the Appendix show clearly these outliers. Removing the renter share variable from the model results in a coefficient of 0.12 for mean gross personal income, rather than the 0.20 when renter share is included. This effect indicates that the pooling of households and properties by geographic area in the data possibly underestimates the relative progressiveness of SV as a property tax base.

The Kakwani index of progressivity change from the tax switch is of a similar magnitude to the LGA-level analysis, with the Lorenz curves for each tax base in Figure A.4 of the Appendix.

Finally, the results for the SA1 level models, with socio-economic status indexes used as independent variables, are shown in Table 4. There is a large and significant relationship between all indexes and the SV/CIV ratio in the area, indicating again that SV is the more progressive tax even across the 160 SA1 areas within each LGA. The coefficient of 0.30 for the IER index implies that a 1\% increase in that index, which is designed to measure

suggested by the coefficients in Table 2 . 
Table 3: SV/CIV ratio analysis and progressivity index (SA2 level)

\begin{tabular}{llll}
\hline \hline & 1 & 2 & 3 \\
\hline $\begin{array}{l}\text { Median gross personal inc. } \\
\text { Mean gross personal inc. }\end{array}$ & $0.17^{* * *}$ & & \\
Mean eq.disp.inc. & & $0.20^{* * *}$ & \\
Renter share & $-0.30^{* * *}$ & $-0.29^{* * *}$ & $-0.14^{* * *}$ \\
\hline $\mathrm{R}^{2}$ & 0.17 & 0.13 & 0.14 \\
\hline Kakwani index & 0.025 & 0.030 & 0.027 \\
Relative Gini increase & 0.25 & 0.33 & 0.42 \\
\hline \hline
\end{tabular}

$\mathrm{SV} / \mathrm{CIV}$ ratio at SA2 level. Income variables are the log of weekly incomes.

economic resources in terms of income and wealth, is associated with an increase in the $\mathrm{SV} / \mathrm{CIV}$ ratio of 0.30 percentage points. The IER also shows the largest Kakwani index of progressivity change, and also the largest relative increase, which arises because a tax on a CIV base a tax is barely progressive by this measure of household economic resources. A visual representation of the Lorenz curves for each tax base and each socio-economic status index are in Figure A.6 of the Appendix.

Table 4: SV/CIV ratio analysis and progressivity index (SA1 level)

\begin{tabular}{|c|c|c|c|c|}
\hline & 1 & 2 & 3 & 4 \\
\hline IRAD & $0.25^{* * *}$ & & & \\
\hline IRD & & $0.19^{* * *}$ & & \\
\hline IER & & & $0.30^{* * *}$ & \\
\hline IEO & & & & $0.30^{* * *}$ \\
\hline LGA controls & $\mathrm{Y}$ & $\mathrm{Y}$ & $\mathrm{Y}$ & $\mathrm{Y}$ \\
\hline $\mathrm{R}^{2}$ & 0.47 & 0.47 & 0.48 & 0.47 \\
\hline Kakwani index & 0.038 & 0.037 & 0.056 & 0.029 \\
\hline $\begin{array}{l}\text { Relative } \quad \text { Gini } \\
\text { increase }\end{array}$ & 0.25 & 0.30 & 5.45 & 0.15 \\
\hline
\end{tabular}

${ }^{*} p<0.1,{ }^{* *} p<0.05,{ }^{* * *} p<0.01 . N=12,889$. Dependent variable is $\mathrm{SV} / \mathrm{CIV}$ ratio at SA1 level. Socio-economic status variables are the log of the indexes.

The results at each of the three geographic levels of analysis all point to SV being the more progressive property tax base. The LGA-level analysis showed that the value of residential property (either SV or CIV) more closely tracks local incomes, while the SA2level analysis showed the importance of the renter share of households on the relationship between household incomes and the SV/CIV ratio. At the SA1 level, the robustness of 
these relationship was demonstrated at a very fine grain geographic level, and in relation to a broad array of household socio-economic metrics that also capture wealth, education and occupational factors.

\section{$4.2 \quad$ Efficiency}

The results of our model variations of Equation 3 are in Table 5. Models 1 to 3 have the number of dwelling construction permits issues as the independent variable, with Models 1 and 2 including council and year controls independently, and Model 3 with both controls. The estimated coefficient for the SV dummy is positive in all models, but only significant when controls are independently included in the model. Models 4 to 6 use construction value as the independent variable, and in these variations the SV dummy coefficient is more robustly positive and significant, falling in the range of 0.20 to 0.51 . This indicates that the effect on construction investment from switching to an SV property tax base could be quite large, in the order of 20 to 50 percent, at least for the short three to five year window following the tax change, which is the range of this data.

Table 5: Dwelling permit and construction value model results

\begin{tabular}{l|rrr|rrr}
\hline \hline & \multicolumn{3}{|c}{ Permits } & \multicolumn{4}{c}{ Construction value } \\
& 1 & 2 & 3 & 4 & 5 & 6 \\
\hline SV dummy & $0.30^{* * *}$ & $0.68^{* * *}$ & 0.14 & $0.51^{* * *}$ & $0.44^{* * *}$ & $0.20^{* *}$ \\
Council controls & $\mathrm{Y}$ & $\mathrm{N}$ & $\mathrm{Y}$ & $\mathrm{Y}$ & $\mathrm{N}$ & $\mathrm{Y}$ \\
Year controls & $\mathrm{N}$ & $\mathrm{Y}$ & $\mathrm{Y}$ & $\mathrm{N}$ & $\mathrm{Y}$ & $\mathrm{Y}$ \\
\hline $\mathrm{N}$ & 181 & 181 & 181 & 190 & 190 & 190 \\
$\mathrm{R}^{2}$ & 0.86 & 0.34 & 0.91 & 0.86 & 0.50 & 0.93 \\
\hline \hline
\end{tabular}

${ }^{*} p<0.1,{ }^{* *} p<0.05,{ }^{* * *} p<0.01$. Independent variables are log quantity for permits, and $\log \$ \prime 000$ for construction value. Permits data was not available for South Melbourne.

We visually present these results in Figure 2. The left panel shows the deviation from the sample mean for the log of council permits (left) and construction value (right) at times relative to the switch from CIV to SV (year one is the first year after the switch). The dashed blue line joins the mean of each year's observations to show the trend that was captured in the previous regression models. The right panel show the same method applied to the value of construction undertaken in each council area. This evidence adds to the case that changes to the rate of land value taxation are non-neutral in terms of their effect on the timing choice for developing vacant and under-utilised land. 

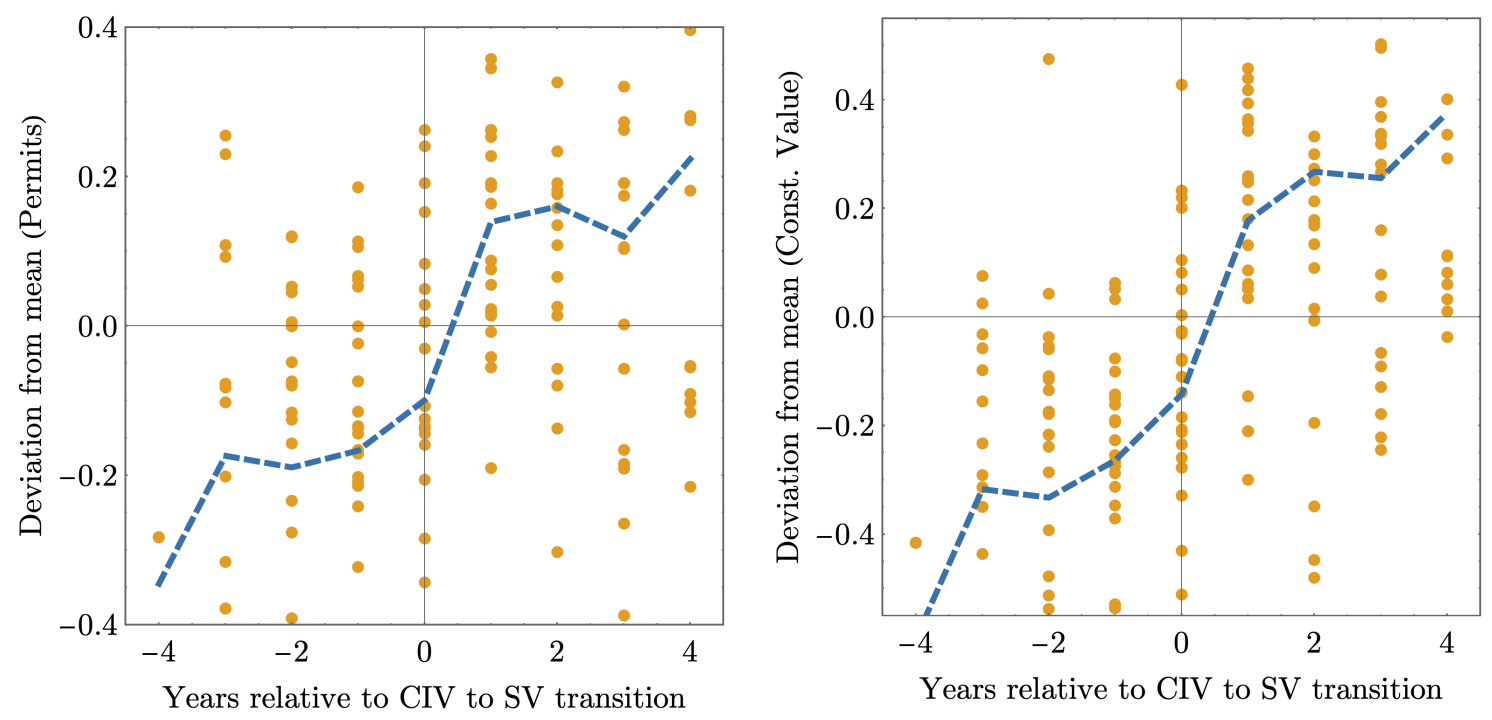

Figure 2: Deviation from sample mean. Left is permits. Right is construction value.

\section{Discussion and Conclusion}

We have found that across and within LGAs in Victoria SV is a more progressive tax base than CIV, as the ratio of SV to CIV increases with incomes. This implies that if councils in Victoria shifted their tax base from CIV to SV, higher income areas would pay more property tax, and lower income areas less. This result seems to go against the popular view in recent policy discussions that CIV better reflects a household's ability to pay property tax. A key reason for this confusion seems to be a misinterpretation of the study by Shand et al. (2007), which showed that in a linear model that CIV has a stronger relationship to household income than SV (coefficient of 4.3 compared to 1.8). But a comparison of the two linear models cannot allow a comparison of the relative relationship because it imposes a fixed SV/CIV ratio across the income distribution. We therefore directly compared the SV/CIV ratio to incomes to demonstrate that a change in the tax base from CIV to SV (maintaining constant total revenue) will increase the progressivity of the property tax system. In other words, SV rather than CIV makes the distribution of tax payable more closely aligned with the distribution of household incomes. Additionally, we directly calculated a measure of the change in the progressivity of raising taxes from each base, showing that SV is consistently more progressive. At the same time, this is likely to mean that, for a revenue-neutral switch from CIV to SV, the tax burden would fall for most property owners, while concentrating the tax burden on the few property owners with vacant ( $7 \%$ of properties in our data) and under-utilised land.

To raise the same revenue from SV rather than CIV would require a $70 \%$ higher per dollar tax rate on average in Victoria, creating a substantial reduction in the incentive to delay investment on vacant and under-utilised properties. We have shown that the timing effect for applying the same tax rate on SV and CIV is theoretically ambiguous (depending 
on expected relative cost changes) but the fact that the tax rate must be substantially higher on vacant and under-utilised properties when property taxes are raised on an SV base suggest to us that there should be large efficiency gains in terms of bringing forward investment timing. Using our panel data of historical changes to LGA tax bases in Victoria we showed that switching from a CIV to SV property tax base increased the yearly value of residential construction investment by $20 \%$, and is likely to have also increased the number of dwelling permits issued, which is consistent with other results (Gemmell et al. 2019). This suggests that the policy debate about property taxes, which has focussed on whether property taxes reflect the cost of service provision to a property, needs to be refocussed on the greater progressivity of site value tax and the increased local construction investment it could generate.

\section{References}

Abelson, Peter. 2006. Local Government Taxes and Charges. Applied Economics.

ABS. 2011. 2033.0.55.001 Census of Population and Housing: Socio-Economic Indexes for Areas (SEIFA), Australia. Australian Bureau of Statistics.

ABS. 2012. 4609.0.55.002 - Land Account: Victoria, Experimental Estimates, 2012. Australian Bureau of Statistics.

ABS. 2018. 6524.0.55.002 - Estimates of Personal Income for Small Areas, 2011-2016. Australian Bureau of Statistics.

ABS. 2019a. 1410.0 - Data by Region, 2013-18. Australian Bureau of Statistics.

ABS. 2019b. 6523.0 - Household Income and Wealth, Australia, 2015-16. Australian Bureau of Statistics.

ABS. 2020. 5506.0 - Taxation Revenue, Australia. Tech. rept. Australian Bureau of Statistics.

Anderson, Phil. 1996. Victoria's Municipal Rating System. Tech. rept. Australian Institute of Urban Studies.

Barbosa, Rafael, \& Skipka, Simon. 2019. Tax Housing or Land? Distributional Effects of Property Taxation in Germany.

Bentick, Brian L. 1979. The impact of taxation and valuation practices on the timing and efficiency of land use. Journal of Political Economy, 87(4), 859-868.

Bowman, John H, \& Bell, Michael E. 2008. Distributional consequences of converting the property tax to a land value tax: Replication and extension of England and Zhao. National Tax Journal, 593-607. 
BRUECKNER, JAN K. 1986. A modern analysis of the effects of site value taxation. National Tax Journal, 49-58.

Cho, Seong-Hoon, Kim, Seung Gyu, \& Roberts, Roland K. 2011. Measuring the effects of a land value tax on land development. Applied Spatial Analysis and Policy, $4(1), 45-64$.

Comrie, John. 2013. In our hands: Strengthening local government revenue for the 21st century. Australian Centre of Excellence for Local Government, University of Technology, Sydney.

DEWLP. 2019a. Property Valuation Statistics. 2016 Revaluation outcomes. Environment, Land, Water and Planning. Victoria State Government.

DEWLP. 2019b. Victorian Local Government Rating System Review - Discussion Paper. Department of Environment, Land, Water and Planning. Victoria State Government.

Drew, Joseph, \& Dollery, Brian. 2015. A Fair Go: A Response to the Independent Local Government Review Panel's Assessment of Municipal Taxation in NSW. Australian Tax Forum, 30, 471.

Duke, Joshua M, \& Gao, TianHang. 2018. An Experimental Economics Investigation of the Land Value Tax: Efficiency, Acceptability, and Positional Goods. Land Economics, 94(4), 475-495.

England, Richard W, \& Zhao, Min Qiang. 2005. Assessing the Distributive Impact of a Revenue-Neutral Shift from a Uniform Property Tax to a Two-Rate Property Tax with a Uniform Credit. National Tax Journal, 247-260.

England, Richard W, Zhao, Min Qiang, \& Huang, Ju-Chin. 2013. Impacts of property taxation on residential real estate development. Journal of Housing Economics, 22(1), 45-53.

ESC. 2020. Fair Go Rates system- Applying for a higher cap. Guidance to councils 202122. Tech. rept. Essential Services Commission.

ESC. 2021. Annual council rate caps. 2021-22. Tech. rept. Essential Services Commission.

Freebairn, John W. 2020. Reforming state taxes on property. Tax and Transfer Policy Institute, working paper, 6.

Gaffney, Mason. 1971. The property tax is a progressive tax. Pages 408-26 of: Proceedings, NTA, 64th Annual Conference, Kansas City, vol. 1971.

Gemmell, Norman, Grimes, Arthur, \& Skidmore, Mark. 2019. Do local property taxes affect new building development? Results from a quasi-natural experiment in New Zealand. The Journal of Real Estate Finance and Economics, 58(2), 310-333. 
IPART. 2016. Review of the Local Government Rating System. Independent Pricing and Regulatory Tribunal. New South Wales.

Kavanagh, Bryan. 1972. South Melbourne building boom: following un-taxing of buildings. Progress, September.

Kavanagh, Bryan. 1975. Untaxing buildings. Progress, March.

Kavanagh, Bryan. 1985. Seymour Shire building permits. Progress, February.

Mills, David E. 1981. The non-neutrality of land value taxation. National Tax Journal, 34(1), 125-129.

Oates, Wallace E, \& Fischel, William A. 2016. Are local property taxes regressive, progressive, or what? National Tax Journal, 69(2), 415.

Oates, Wallace E, \& Schwab, Robert M. 1997. The impact of urban land taxation: The Pittsburgh experience. National Tax Journal, 1-21.

Plummer, Elizabeth. 2010. Evidence on the distributional effects of a land value tax on residential households. National Tax Journal, 63(1), 63.

Pollock, Richard L, \& Shoup, Donald C. 1977. The effect of shifting the property tax base from improvement value to land value: an empirical estimate. Land Economics, $53(1), 67-77$.

Shand, David, Horsley, Graeme, \& Cheyne, Christine. 2007. Funding Local Government. Local Government Rates Inquiry. Department of Internal Affairs.

SRO. 2021. Land tax current rates. Tech. rept. State Revenue Office. Victoria.

YANG, ZHOU. 2018. Differential effects of land value taxation. Journal of Housing Economics, 39, 33 - 39 .

\section{Appendix}

The condition for delay is that the present value of Project B exceed the value of Project A, which is the highest returning project today. Following from Bentick (1979) and Mills (1981) we start by calculating the net present value (NPV) of each project, then ascertaining the condition at $0<t<T$ that is required for indifference between each project.

Project A: For the no tax and tax on SV cases, the current land value solves for the condition

$$
\frac{r_{e n t}-c_{A} r-b V}{V}=r
$$


which implies that the capitalised net rent (rent net of interest on construction costs and property tax) at the discount rate $r$, and gives

$$
V_{A}=\frac{\operatorname{rent}_{A}-c_{A} r}{r+b}
$$

When $b=0$ this is just the net rent capitalised at $r$.

Project B: For the no tax and tax on SV cases, the land value at time $t$ solves for the condition

$$
V=\frac{\operatorname{rent}_{B}-c_{B} r}{r+b}
$$

Between time 0 and $T$ the value of Project 2 must increase at a rate that provides the property owner a return of $r$ after taxes are paid. At any time $t$, property taxes paid are $b V_{t}$, so the condition for estimating the present value of Project $\mathrm{B}$ is

$$
\frac{\dot{V}_{t}-b V_{t}}{V_{t}}=r
$$

or

$$
\dot{V}_{t}=(r+b) V_{t}
$$

implying that $V_{t}$ grows exponentially at the rate $(r+b)$ and therefore the discounted value of Project B is

$$
V_{B}=e^{-(r+b) T} \frac{\operatorname{rent}_{B}-c_{B} r}{r+b} .
$$

The condition for delay is that $V_{A}<V_{B}$, or

$$
\frac{\operatorname{rent}_{A}-c_{A} r}{r+b}<e^{-(r+b) T} \frac{r e n t_{B}-c_{B} r}{r+b}
$$

which simplifies to our result for the no tax $(b=0)$ and SV tax scenario of

$$
\left(\text { rent }_{A}-c_{A} r\right)<e^{-(r+b) T}\left(\text { rent }_{B}-c_{B} r\right) .
$$

Tax on CIV: We note that from Project B prior to time $T$ that $S V=C I V$, and that after either project is completed that the tax falls on the capitalised rent alone (i.e. not net of the construction cost). In this tax setup 


$$
V_{A}=\frac{r e n t_{A}}{r+b}-c_{A}
$$

and at time $T$ the value of Project $B$ is

$$
V=\frac{\operatorname{rent}_{B}}{r+b}-c_{B}
$$

When $0<t<T$ the SV and CIV of Project B are the same (since there are no capital improvements yet made), so that the growth rate in equilibrium over this period to be indifferent to the two projects must be $(r+b)$, meaning that the present value of Project $\mathrm{B}$ is

$$
V_{B}=e^{-(r+b) T}\left[\frac{r e n t_{B}}{r+b}-c_{B}\right] .
$$

Comparing the two project choices in the CIV case is slightly different, but the same $V_{A}<V_{B}$ delay condition applies, and we show that condition and simplify

$$
\begin{gathered}
\frac{\text { rent }_{A}}{r+b}-c_{A}<e^{-(r+b) T}\left[\frac{\text { rent }_{B}}{r+b}-c_{B}\right] \\
\frac{\text { rent }_{A}-c_{A} r-c_{A} b}{r+b}<e^{-(r+b) T} \frac{\text { rent }_{B}-c_{B} r-c_{B} b}{r+b}
\end{gathered}
$$

to give our condition for delay in the case of a property tax levied on CIV.

$$
\left(\text { rent }_{A}-c_{A} r\right)<e^{-(r+b) T}\left(\text { rent }_{B}-c_{B} r\right)+b\left(c_{A}-e^{-(r+b) T} c_{B}\right) .
$$




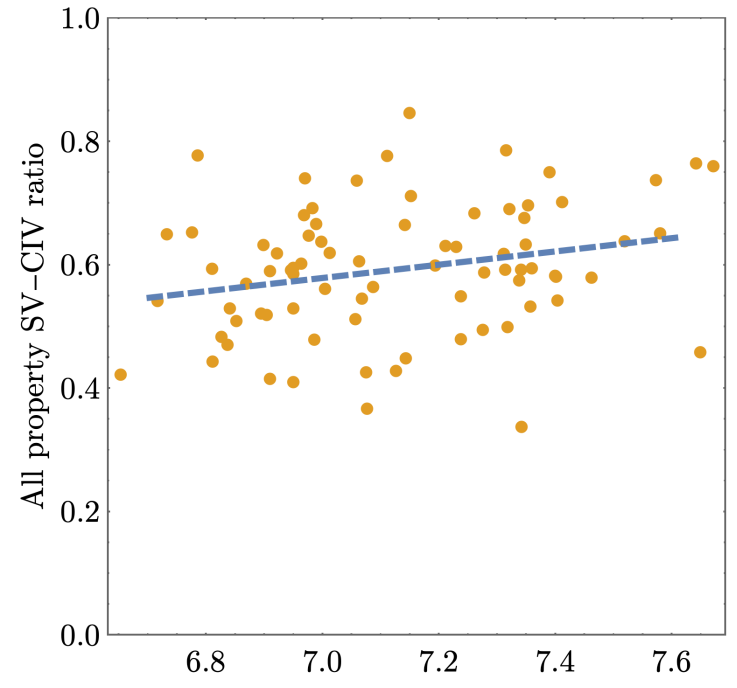

Log median gross household income

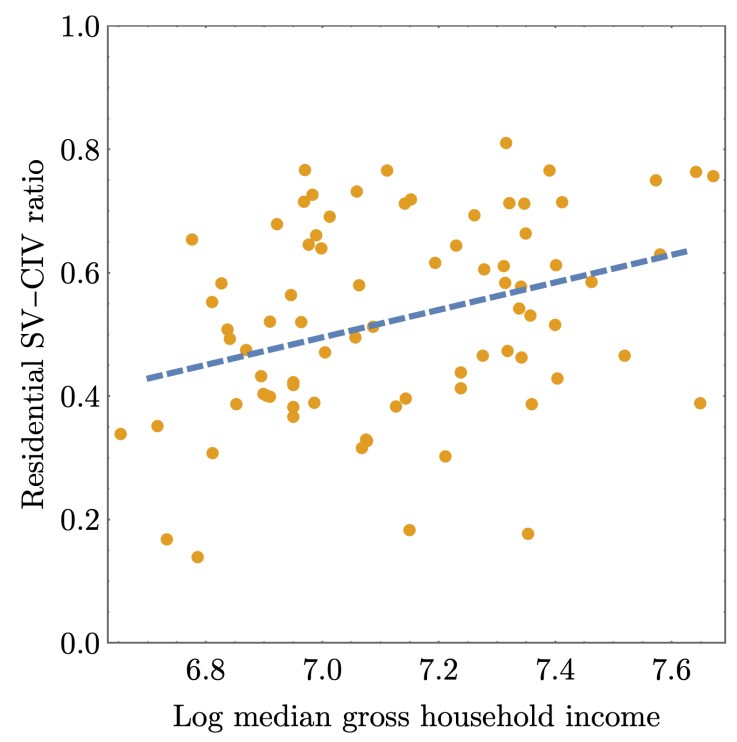

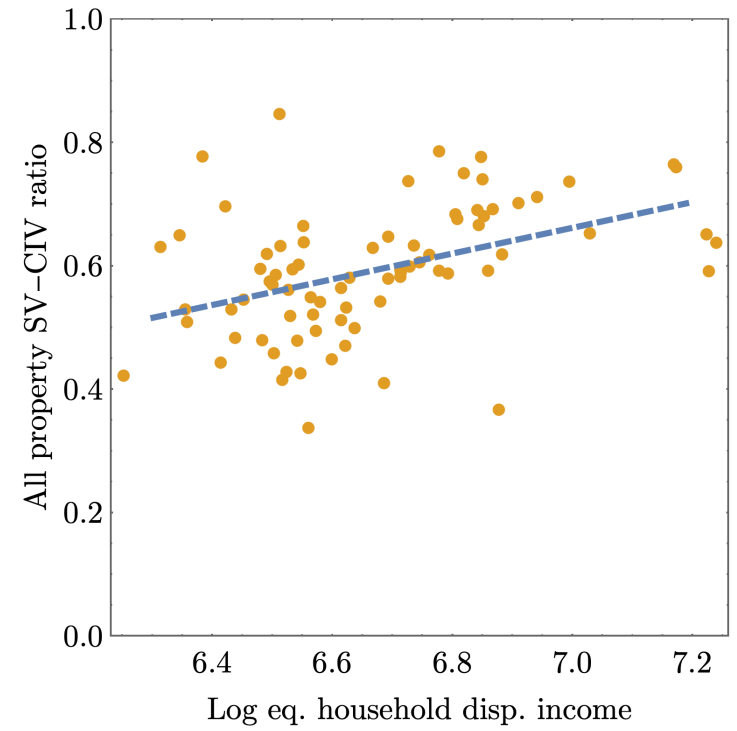

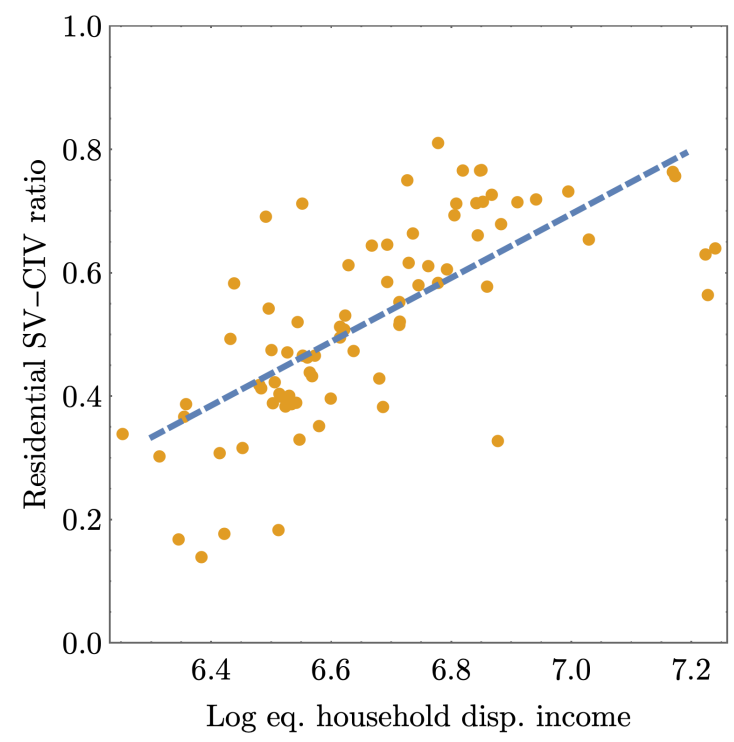

Figure A.1: LGA-level SV/CIV ratio and income metrics (incl. best fit). 

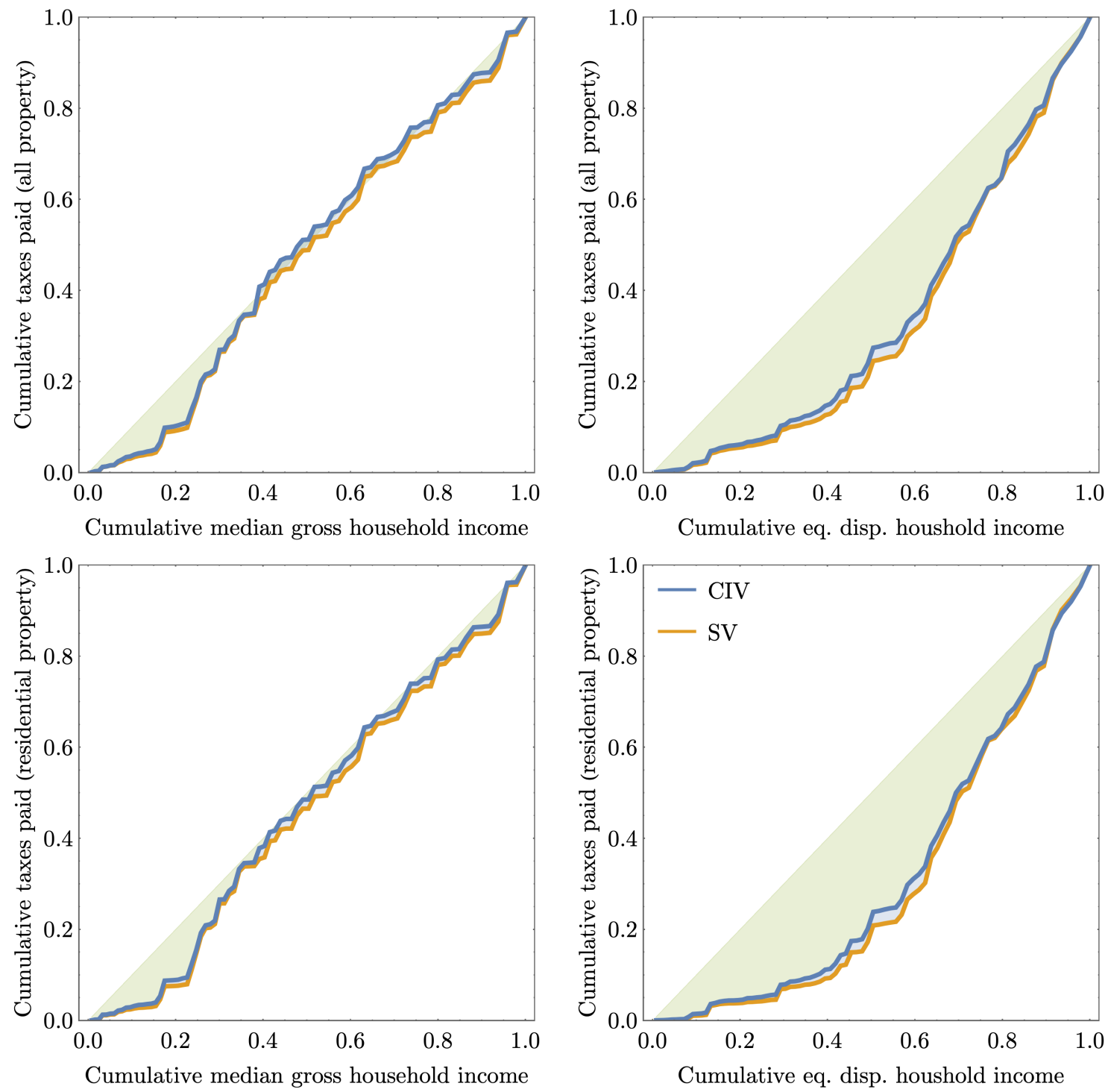

Figure A.2: LGA-level Lorenz curves for SV and CIV tax base (by income and prop. type) 

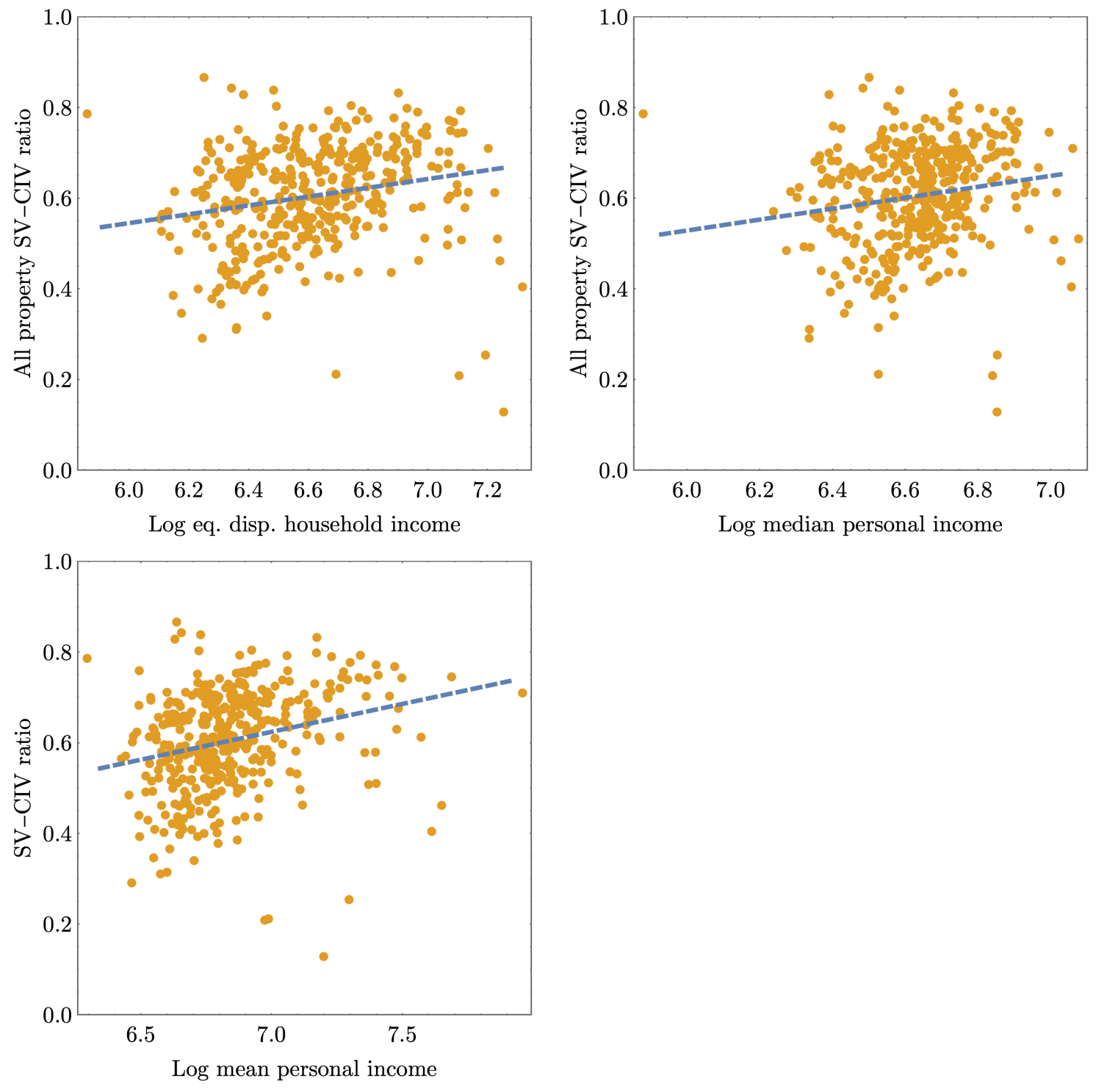

Figure A.3: SA2-level SV/CIV ratio and income metrics (incl. best fit). 

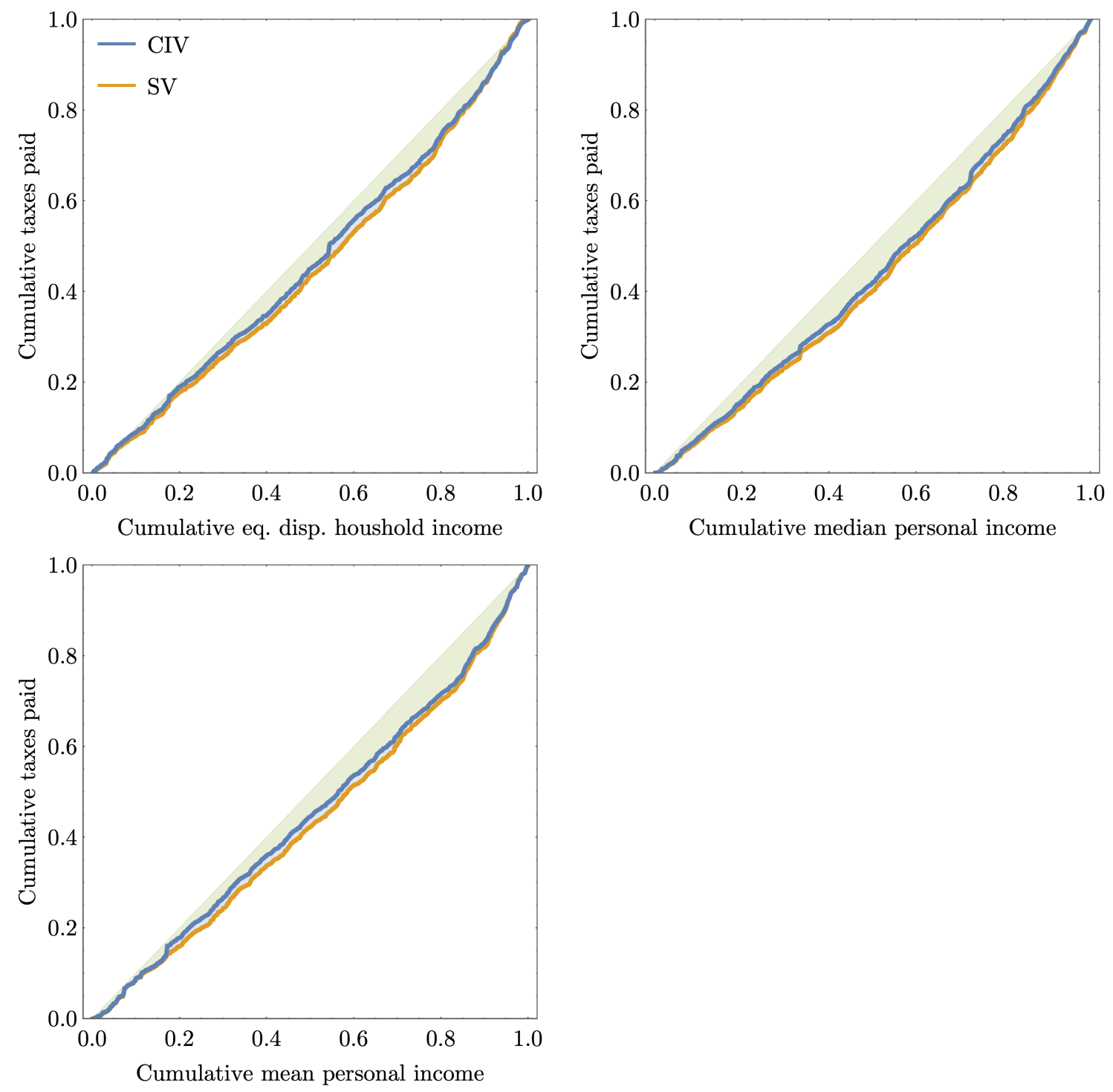

Figure A.4: SA2-level Lorenz curves for SV and CIV tax bases (by income type) 

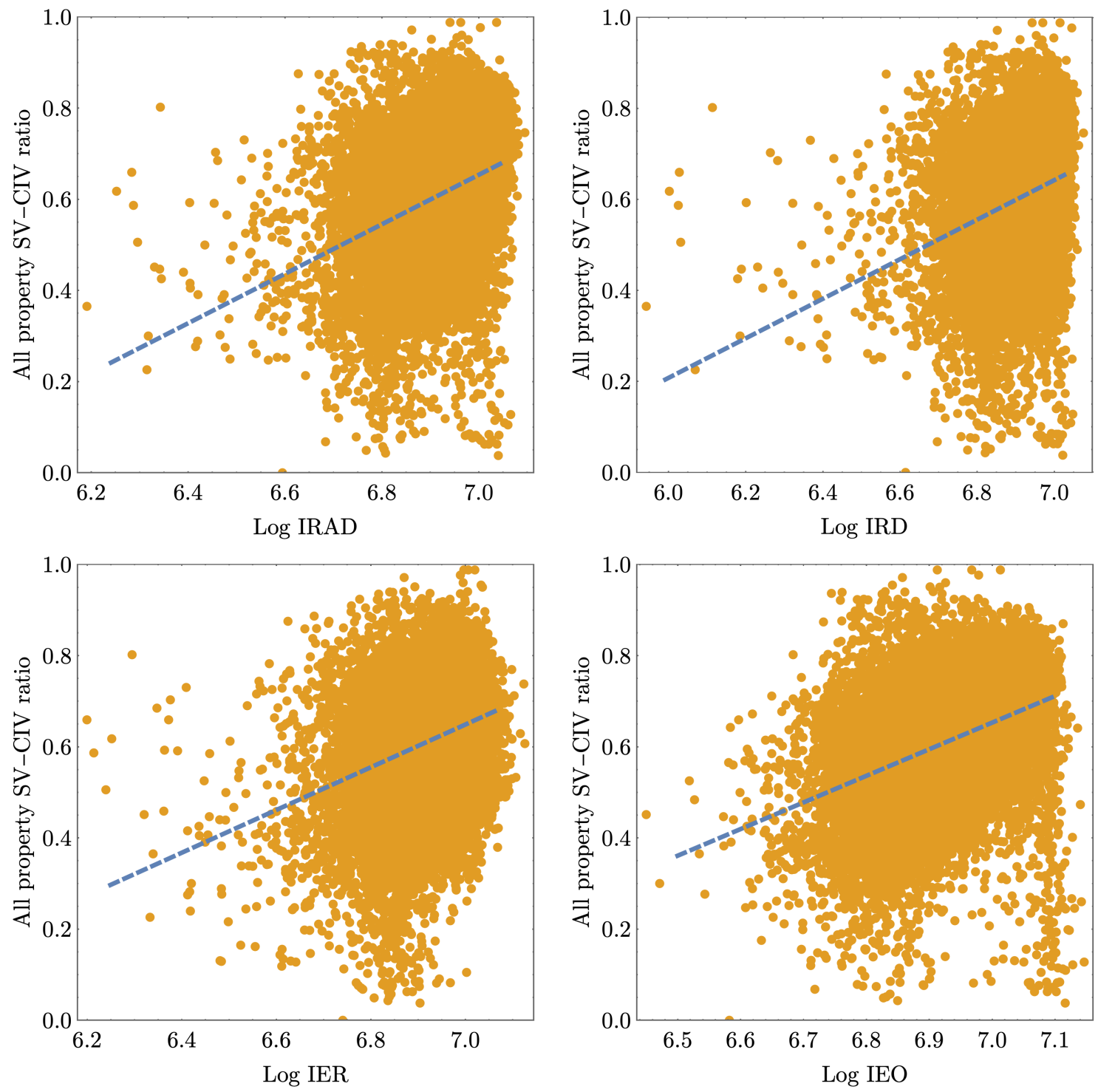

Figure A.5: SA1-level SV/CIV ratio and socio-economic indexes 

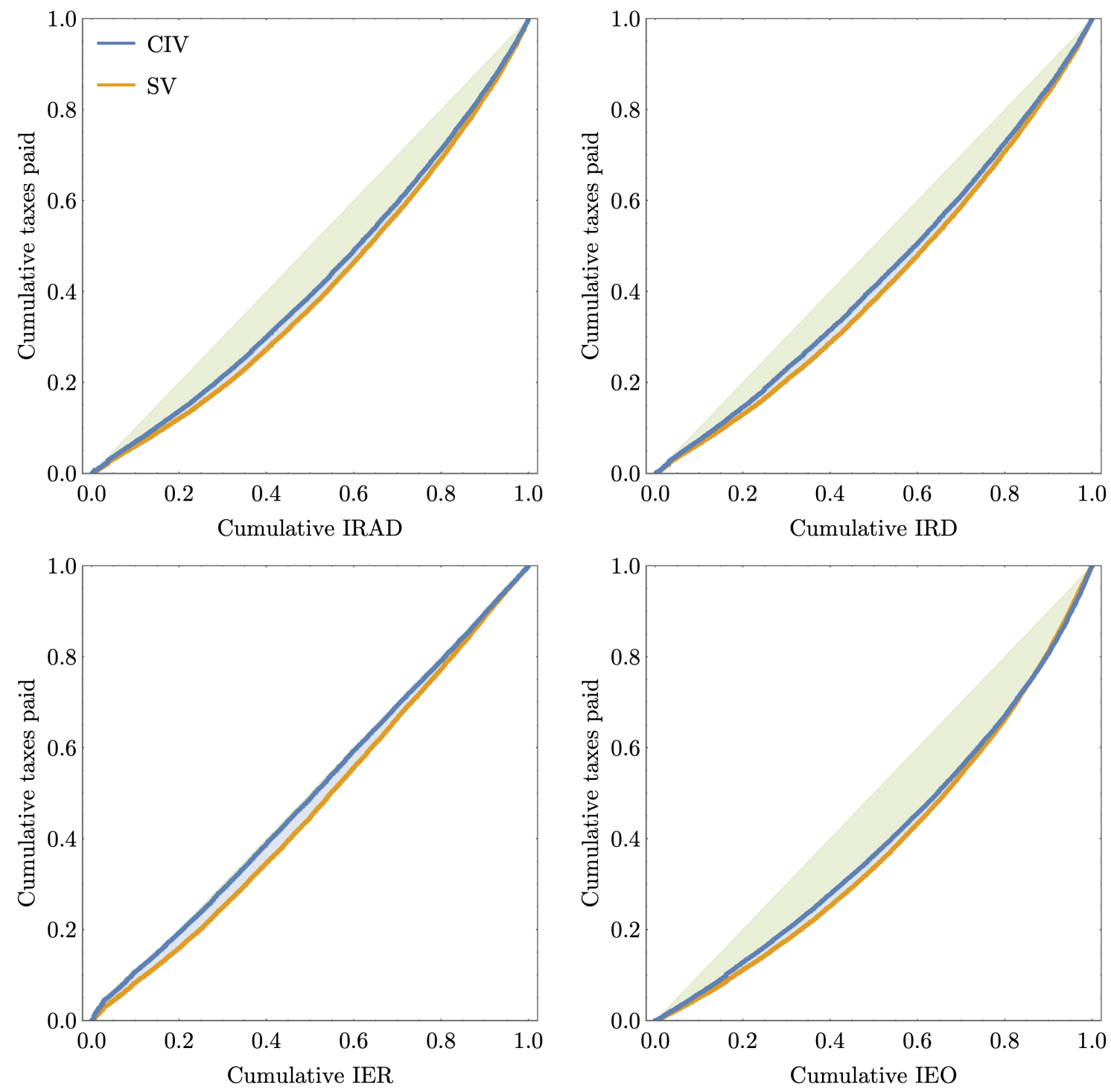

Figure A.6: SA1-level Lorenz curves for SV and CIV tax bases (by socio-economic index) 
Table A.1: Summary of Victorian data at all levels of geography

\begin{tabular}{|c|c|c|c|c|c|}
\hline Geography & Metric & Min & Median & Mean & $\operatorname{Max}$ \\
\hline \multirow{14}{*}{ LGA } & CIV total ( $\$$ billion $)$ & 1.3 & 9.9 & 23.4 & 110.9 \\
\hline & SV total ( $\$$ billion $)$ & 0.7 & 5.1 & 14.9 & 84.8 \\
\hline & $\mathrm{SV} / \mathrm{CIV}$ ratio & 0.34 & 0.59 & 0.59 & 0.85 \\
\hline & Number of assessments ('000) & 3,103 & 25,576 & 36,758 & 118,861 \\
\hline & Median household income (\$/week) & 775 & 1,196 & 1,286 & 3,103 \\
\hline & Mean equivalised income (\$/week) & 519 & 752 & 808 & 1,393 \\
\hline & Share of rental households (\%) & 8.6 & 23.0 & 25.2 & 65.9 \\
\hline & Residential share of CIV (\%) & 8.9 & 69.0 & 62.5 & 92.3 \\
\hline & Residential share of SV (\%) & 1.9 & 68.7 & 59.1 & 95.3 \\
\hline & Rural share of CIV (\%) & 0 & 15.9 & 22.1 & 89.0 \\
\hline & Rural share of SV (\%) & 0 & 18.4 & 29.7 & 97.6 \\
\hline & Vacant lot share, all types (\%) & 0.29 & 6.4 & 7.1 & 25.6 \\
\hline & Vacant lot share, residential (\%) & 1.6 & 6.7 & 6.8 & 18.2 \\
\hline & Vacant lot share, commercial (\%) & 0.52 & 3.8 & 4.5 & 22.1 \\
\hline \multirow{8}{*}{ SA2 } & CIV total ( $\$$ billion $)$ & 0.02 & 2.2 & 2.8 & 14.0 \\
\hline & SV total ( $\$$ billion) & 0.01 & 1.3 & 1.7 & 10.4 \\
\hline & $\mathrm{SV} / \mathrm{CIV}$ ratio & 0.29 & 0.61 & 0.61 & 0.87 \\
\hline & Population & 26 & 11,486 & 12,421 & 27,946 \\
\hline & Share of rental households (\%) & 4.7 & 21.9 & 24.3 & 76.6 \\
\hline & Median personal income (\$/week) & 357 & 770 & 768 & 1,183 \\
\hline & Mean personal income (\$/week) & 541 & 899 & 964 & 2,858 \\
\hline & Mean equivalised income $(\$ /$ week $)$ & 350 & 736 & 767 & 1,505 \\
\hline \multirow{8}{*}{ SA1 } & CIV total $(\$$ million $)$ & 0.7 & 70.1 & 91.8 & 3,967 \\
\hline & SV total ( $\$$ million $)$ & 0 & 43.1 & 57.4 & 2,020 \\
\hline & $\mathrm{SV} / \mathrm{CIV}$ ratio & 0 & 0.62 & 0.60 & 0.99 \\
\hline & Population & 22 & 409 & 427 & 6,711 \\
\hline & IRAD & 488 & 1,018 & 1,005 & 1,205 \\
\hline & IRD & 381 & 1,028 & 1,009 & 1,182 \\
\hline & IER & 492 & 1,007 & 1,001 & 1,242 \\
\hline & IEO & 632 & 1,009 & 1,013 & 1,269 \\
\hline
\end{tabular}

LGA data is for 2016. SA2 and SA1 data is from 2011 and derived from the census of that year. Number of data points: $\mathrm{LGA}=79, \mathrm{SA} 2=392, \mathrm{SA} 1=12,899$. Incomes are for household unless otherwise noted. Total CIV in Victoria in 2016 was $\$ 1.85$ trillion, $57 \%$ more than the total SV of $\$ 1.18$ trillion. IRAD is the Index of Relative Socio-economic Advantage and Disadvantage, IRD is the Index of Relative Socio-economic Disadvantage, IER is the Index of Economic Resources, and IEO is the Index of Education and Occupation. 